\title{
Research
}

\section{What Constitutes Success in Pacific Island Community Conserved Areas?}

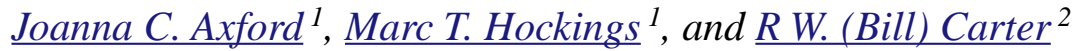

\begin{abstract}
In recent years, few if any community conserved areas (CCAs) in the Pacific island region have been regarded as being successful. However, as success is rarely defined, what constitutes "success" is not clear. This paper reports an investigation into the way "outsiders" perceive success in Pacific island CCAs. An exploratory survey revealed six umbrella themes of success: the locus of control; local benefits; resource aspects; management; external stakeholder involvement; and sustainability. Multivariate analysis distinguished two groups, a Big picture group and a Locally focused group. These differ in how they define success, as well as their organizational alignment. The Big picture group, largely from funder agencies and international NGOs, were focused on the broad issues of success, especially the sustainability of CCAs. The Locally focused group was concerned with the practical workings and needs of successful CCAs in the Pacific; many in this group were based with Pacific island governments and NGOs or CCAs. The study concludes that success in CCAs should not be defined solely on project objectives, especially when these have been developed by an external entity or under their guidance. If they are, high rates of failure are to be expected.
\end{abstract}

Key Words: community conserved area; conservation; Pacific islands; perception; protected area; success

\section{INTRODUCTION}

Community conserved areas (CCAs) are a protected area approach where the indigenous people and/or local community voluntarily conserve their land or sea area through customary or other effective means, and in which they have a central management role (Borrini-Feyerabend et al. 2004). Internationally there is growing recognition of CCAs (Phillips 2003). In the Pacific islands region, CCAs are increasingly supported at local, regional, and international levels as an appropriate conservation model. This reflects their social and ethical appropriateness (Baines et al. 2002, Aswani 2005, Cinner and McClanahan 2006) and the difficulties encountered by government-led protected area approaches.

Despite the rise of CCAs in the Pacific, few have been assessed as successful, and many have not been sustained following intervention (e.g., McCallum and Sekhran 1997, Salafsky et al. 2001, Baines et al. 2002). Failure has been attributed to a lack of capacity to sustain CCAs in the absence of external support and a general lack of community ownership and effective management to achieve conservation objectives (Sekhran 1996, van Helden 1998, Baines et al. 2002). This reflects international trends reporting a dearth of successful integrated and community-based initiatives (Lepp and Holland 2006, Berkes 2007, Garnett et al. 2007). This history of failed initiatives has led to increased emphasis on what is required to achieve success in CCAs. Outsiders who invest in community-based initiatives desire optimal return on their investment and are, therefore, interested in the likelihood of success (Crawford et al. 2006). A lack of perceived success by those outside the local CCA community could lead to a withdrawal of support for the community-based approach to conservation (Pollnac et al. 2001, Horwich and Lyon 2007).

But what is does success mean? Success and failure are commonly used to describe the status of a CCA, but these terms are rarely clearly or consistently defined. This may reflect an implicit understanding that deciding on a project's goals and how to measure progress toward these goals will provide an operational definition of success (Salafsky et al. 2002, Robinson and Redford 2004, Stem et al. 
2005). In this sense, what constitutes success will often be determined at the beginning of a project based on a particular value system. It is assumed that a CCA will be deemed successful when it has reached its goals and objectives. However, this may represent a narrow view of CCA success and may not encompass the views of all actors.

The prevalence of implicit understandings rather than explicit definitions of success may lead to misunderstanding about what success is and how it is to be reached. As evaluation criteria are often not made explicit until near the end of the project, different assumptions regarding success will rarely become overt until the project evaluation commences. Many community-based conservation evaluations are conducted by outsiders based on their objectives and criteria for success (Roe et al. 2000). For example, the South Pacific Biodiversity Conservation Programme (SPBCP) -implemented and funded through the United Nations Development Programme (UNDP) and executed by the Secretariat of the Pacific Regional Environment Programme (SPREP) - used CCAs as a tool for achieving biodiversity conservation through the sustainable use of biological resources. Over a 10year period, the SPBCP supported 17 CCAs in 12 Pacific island countries. In 2001, a UNDPappointed team evaluated the SPBCP against objectives defined in the SPBCP Project Document (developed 10 years earlier). The Evaluation team concluded that although there were some successes, the Programme failed to meet its objectives (Baines et al. 2002). Not all members of the region's conservation community supported this finding. Many felt the evaluation did not represent the true impact of the programme. This may reflect the difference between formal evaluations based on program objectives and intuitive evaluations of a broader range of non-formalized objectives and expectations that emerged as the program was implemented.

Success is often considered in terms of "what leads to success?" It is the emphasis on this question, rather than "what is success?" that has led to the dominance of efforts to delineate factors influencing success (Pomeroy et al. 1997, Pollnac et al. 2001); measures of success (Gerber et al. 2000, Parrish et al. 2003); and indicators of success (Kates et al. 2005). This discussion of factors and indicators has, to a large degree, dominated the success debate. A focus on what constitutes success, may assist in understanding what we want to achieve rather than assuming a common understanding of "success" (e. g., reaching predetermined goals or conservation success).

Success in CCAs is an increasingly debated issue, challenged by conservation and development professionals, academics and local actors (e.g., Smith-Korfmacher 1998, Brechin et al. 2002, Agardy et al. 2003, Christie 2004, Horwich and Lyon 2007). Given the perception that Pacific CCAs are failing and the lack of clarity as to what success means, this study investigates the nature of success in Pacific island CCAs. If we are to understand why CCAs are failing to succeed, then it is important to unravel the concept of success itself. To examine this issue, we investigated the following questions:

- How is success in Pacific island CCAs perceived by outsiders? and

- Do outsiders share a vision of success or are there multiple perceptions?

This paper explores the concept of success in Pacific island CCAs from the perspective of "outsiders" such as practitioners, implementers, and funders working with Pacific island CCAs. Limited evaluations and research into CCA success in the region meant it was necessary to map out the "terrain" of the research area through an exploratory survey.

\section{METHODS}

A qualitative self-administered questionnaire was sent to outsiders involved with Pacific island CCAs. The Pacific islands here refers to the island states of Melanesia, Micronesia, and Polynesia, it does not include Australia or New Zealand. The questionnaire was simple and purposefully open to a variety of responses. To avoid providing a prescribed framework for success, the questionnaire specifically did not ask for perspectives on environmental, social or management elements of success as other studies have done (e.g. Alder 1996, Pollnac et al. 2001, Webb et al. 2004, Cinner 2005). Two general questions were asked:

1. Describe what you believe would make an area a 'successful' Pacific Community Conserved Area (define success however you want); and 
2. Describe what you believe would make an area a 'failure' as a Pacific Community Conserved Area (define failure however you want).

The exploratory nature of the research meant it was appropriate for the questions to be open rather than closed. Generally, open ended-questions are used sparingly in self-administered surveys (Aldridge and Levine 2001) because of possible misinterpretation of questions by participants, more arduous analysis, and potential researcher bias (Bryman 2001, Babbie 2005). Despite these difficulties, open-ended questions can play an important role, especially in probing views on salient issues (Aldridge and Levine 2001). In this survey, open-ended questions allowed insight into the topic with minimal prompting, allowing respondents to draw from their experience and express views in their own words. Personal perspectives rather than formal organizational positions were sought. Additional questions were included to provide an indication of the respondents' experience and the basis of their knowledge, including years working in Pacific conservation, position, and organizational alignment.

The survey population included site-level personnel such as committee members, field staff, and program-level personnel including international and national NGOs, government agencies, and funders. A base list was taken from participants at the Seventh Pacific Islands Conference on Nature Conservation and Protected Areas, held in 2002 in the Cook Islands. As the only large regional conference on nature conservation in the Pacific islands, attended by approximately 300 people, this was an appropriate source of experts and practitioners. Additional surveys were sent to individuals known to the researcher or recommended by other respondents.

The population sample was geographically widely dispersed. A self-administered mail-out survey enabled wide coverage and was most cost effective (Mangione 1995). Two hundred and thirty surveys were sent by airmail $(n=190)$ and email $(n=40)$. Two reminders were sent by email. Seventeen percent $(n=39)$ of the surveys did not reach informants because of incorrect addresses.

Surveys were returned by 65 respondents (34\% of delivered surveys). The survey was an exploratory investigation, therefore broad representation rather than a high response rate was acceptable. The response population included representatives from most major organizations active within the region as well as local NGOs and governments. Respondents represented different positions in relation to Pacific island CCAs, for example different occupations, organizations, interests, geographical areas, and experiences. Respondents from international NGOs and conservation funders dominated the returned surveys constituting almost half of all respondents. Individuals from local NGOs and governments collectively constituted approximately one-third of the returned survey population. A third of the respondents had more than 10 years' experience working in Pacific island conservation issues. Less than $15 \%$ had $\leq 2$ years' experience.

Qualitative content analysis was used to inductively reveal and construct meaning from the data (Bryman 2001). Categories were developed as terms and concepts emerged from the data rather than being predetermined (Patton 2002). The focus of the survey's analysis was to demonstrate variance, scope, and conceptual distinctions. A classification system of six broad categories of independent variables was inductively developed. These broad categories were: (1) the community as the locus of control; (2) local benefits; (3) resources; (4) management; (5) external involvement; and (6) sustainability (i.e., CCA management longevity). These six independent variables have 12 related sub-categories (Table 1).

Respondents approached the issues of success and failure in two ways. Some articulated their response by describing what was needed to make a CCA successful-listing what they saw as the "ingredients" for success. Others responded by describing what a successful CCA would look likedeveloping a "picture" of success. For example, an ingredient response often began with qualifiers such as "a successful community project would need..." whereas a picture response might start with "The project is... ." Some participants articulated their response as a mixture of ingredients and pictures. In addition to coding broad categories and subcategories of independent variables, responses were also coded as either an ingredient or picture response.

The coding system was conducted at the subcategory level as presence-absence. Scores were not weighted according to how many times a 
Table 1. Classification system used in coding independent variables. This table provides detailed explanation of the six broad categories and 12 sub-categories that were developed inductively as part of an opening coding process. Each returned survey was coded using this classification system.

\begin{tabular}{l}
\hline Broad Category \\
\hline 1. Locus of control-responses \\
pertaining to who should be driving \\
and supporting the area (namely the \\
local community), and the specific \\
local social characteristics that are \\
required.
\end{tabular}

1.2 Local support

2. Local benefits-responses regarding the benefits that should be provided for the local community, $i$. e., satisfaction of local needs or provision for incentives.

3. Resource focus-responses that indicated that success depends on the area being suitable for conservation based on its resources, which are either socially defined or ecologically defined.

4. Management-responses regarding the appropriateness of management style, operations, structure, and capacity. ristics satisfied incentives Style

\section{Sub-category Sub-category Explanation}

$\begin{array}{ll}\text { 1.1 Locally } & \text { CCA is driven (initiated and motivated), controlled, and managed } \\ \text { driven } & \text { by the local community, rather than being externally driven. For } \\ & \text { example: } \\ & \text { "the conservation area must be a community-driven project." }\end{array}$

CCA is driven (initiated and motivated), controlled, and managed example:

"the conservation area must be a community-driven project."

Strong support and demonstrated commitment (from local leaders and the whole community) for the CCA, as well as active community participation and cooperation. For example: "the community freely volunteers their time to the conservation area."

1.3 Local Strength of community structures and traditions, i.e., strong (social) characte- leadership; community virtues, i.e., patience; absence of land disputes; belief/willingness for conservation; ownership and knowledge of the CCA. For example:

"Absence of over-inflated community expectations about what conservation will deliver."

2.1 Local needs Satisfaction of local social, cultural, and economic needs, including: education, skills, capacity, power, subsistence, health, and wellbeing. For example:

"community feels that their conservation area is making a useful contribution to the village and its people."

2.2 Provision of

Development of alternative income-generating activities, monetary compensation, and increased resources for local use. For example:

"pressure is always there for the community to touch our resources but...alternative income generation to counter this would (help) avoid failure."

3.1 Locally Issues of locally sustainable resource use, socially and culturally defined resource appropriate, locally defined and designed CCA. For example: (social) "The most successful...are modest, small, at times temporally and spatially shifting."

3.2 Ecologically Ecological site selection and design, ecological effectiveness and defined conservation outcomes. For example:

"The area is not degraded and able to yield increases in abundance and diversity."

4.1 Appropriate

Specific to the social, cultural,and economic environment of the Pacific islands, and particular local community contexts. For example:

"...failure would come when a Western-type management style is imposed on people who have no previous concept of the conventional protected areas." 
5. External involvement-responses regarding the role and nature of external (i.e., NGO, government, funders, and individual) support and interaction.
4.2 Appropriate operations and structure

Locally appropriate and sensitive monitoring and enforcement; relevant financial and administration structures; effective local rules or local policy supporting the CCA; public awareness and education. For example:

"... communities are proactively managing the natural resources ... having specific measures in place to monitor their success and the financial resources to implement management strategies."

4.3 Adequacy of Established or the development of local management capacity and management capacity

self-reliance. Including financial, administrative, and conservation management. For example:

"the community is not dependent on outside for continued management of the CCA."

5.1 Nature of external involvement

\subsection{Type of} support

No subcategories.
How external stakeholders relate to the local community, appropriateness of involvement, and specific virtues that they should have and pursue, i.e., external ideas and values not imposed; not money driven; sensitivity and awareness of potential impact of external presence. For example:

"... the donor has limited influence on what is happening. The money has come with no strings attached and the donor has realistic expectations of the outcome required."

The ways the external party(ies) should or should not support CCAs-investment and the type of support. For example: "the government must recognize the community's right to establish and enforce the conservation area."

"Sustainability" was considered by some respondents to be the foundation of success, and all other success elements facilitate, enable or lead to sustainability, and therefore, success. For example:

"I believe a CCA is successful when its management is able to meet both resource-conservation and income-generation objectives in a sustainable manner." particular element was noted; for example, if a respondent was coded at all three of the management sub-categories, this was given only one mark at the broad category level. Analysis of the data using the classification system considered both success and failure responses together because they were frequently opposite sides of the same issue.

To investigate patterns in how participants perceive success, a multivariate cluster analysis of results was undertaken using the numerical analysis package PATN v2.3.1 (Belbin 1995). The similarity between respondents, based on six independent variables, was assessed using the Bray-Curtis association distance metric and flexible unweighted pair group method with arithmetic mean fusion strategy (Bray and Curtis 1957, Belbin 1995).

\section{RESULTS: PERCEPTIONS OF SUCCESS AND FAILURE}

Respondents discussed Pacific island CCA success and failure in relation to their knowledge and experience. Respondents acknowledged the multidimensional and subjective nature of success; but none contested the ideal of success. Respondents considered each of the six broad categories, and 12 sub-categories, in a variety of ways (Table 2). Most respondents covered a range of topics and, therefore, were coded for a combination of the categories. A few mentioned only one or two issues in their response, but all categories were noted by more than $40 \%$ of respondents. The broad categories, "management" and "locus of control," were noted most commonly and "sustainability" and "resource focus" were noted least frequently (Table 2). 
Table 2. The frequency of coded responses at each level of success category. Scores for each category, sub-category, and ingredient and picture represent the percentage of the total respondents $(n=65)$. There was no double counting between categories and sub-categories. If a respondent discussed the need for a successful CCA to be locally driven and supported, they were coded at the sub-category level-locally driven (Ingredient) and locally supported (Ingredient), but only once at the broad category-locus of control. The scores were not weighted.

\begin{tabular}{llllll}
\hline \hline Broad Category & Score & Sub-category & Score & Ingredient & Picture \\
\hline Locus of control & $94 \%(n=61)$ & Locally Driven & $46 \%(n=30)$ & $26 \%(n=17)$ & $25 \%(n=16)$ \\
& & Local Support & $60 \%(n=39)$ & $31 \%(n=20)$ & $34 \%(n=22)$ \\
& & Local Characteristics & $77 \%(n=50)$ & $48 \%(n=31)$ & $43 \%(n=28)$ \\
Local benefits & \multirow{2}{*}{$72 \%(n=47)$} & Needs Satisfied & $52 \%(n=34)$ & $9 \%(n=6)$ & $45 \%(n=29)$ \\
& & Provision of Incentives & $37 \%(n=24)$ & $20 \%(n=13)$ & $19 \%(\mathrm{n} 12)$ \\
Resource focus & \multirow{2}{*}{$63 \%(n=41)$} & Locally Defined & $26 \%(n=17)$ & $20 \%(n=13)$ & $8 \%(n=5)$ \\
& & Ecologically Defined & $49 \%(n=32)$ & $15 \%(n=10)$ & $42 \%(n=27)$ \\
Management & \multirow{2}{*}{$100 \%(n=65)$} & Appropriate Style & $91 \%(n=59)$ & $68 \%(n=44)$ & $43 \%(n=28)$ \\
& & Operations and Structure & $74 \%(n=48)$ & $46 \%(n=30)$ & $34 \%(n=22)$ \\
& & Adequate Capacity & $57 \%(n=33)$ & $12 \%(n=8)$ & $46 \%(n=30)$ \\
External involvement & $77 \%(n=50)$ & Nature of Involvement & $54 \%(n=35)$ & $48 \%(n=31)$ & $14 \%(n=9)$ \\
& & Type of Support & $54 \%(n=35)$ & $35 \%(n=23)$ & $23 \%(n=15)$ \\
\hline
\end{tabular}

The dimensions of success (Table 1) provide an overview of what constitutes success in Pacific island CCAs for the survey participants. Local social characteristics and the management approach and style were part of most respondents' success interpretations. Respondents often remarked on the complexities of the sociocultural and political environment of the Pacific islands region. Therefore, the focus was on matching the characteristics of Pacific island communities to an appropriate style of management that would enable a more effective process. This may, in part, explain why respondents focused on the local community and the approach and process of management rather than conservation outcomes such as biodiversity conservation.

\section{Comparative Cluster Analysis}

Multivariate cluster analysis of similarity of the broad category independent variables identified two major groups (Fig. 1). The dendrogram provides a representation of the relationship between respondents on the basis of their coded responses. The respondents are classified into discrete clusters based on similarity.

At the broad category level, the main difference between the two groups is the "sustainability" variable. Most respondents in Group $1(n=34)$ did not mention CCA sustainability in their survey response, whereas all members of Group $2(n=31)$ considered "sustainability" to be a component of a successful or failed CCA. Further investigation of these two groups highlights a number of additional characteristics that are shared between members of 
Fig. 1. Dendrogram classification of success respondents (clustering-intensity coefficient beta $=-0.10$; stress of 0.1763 ). The analysis identifies two main respondent clusters, labeled Group 1 and Group 2. The numbers represent respondents and are provided only to demonstrate the analysis process and respondent clusters.

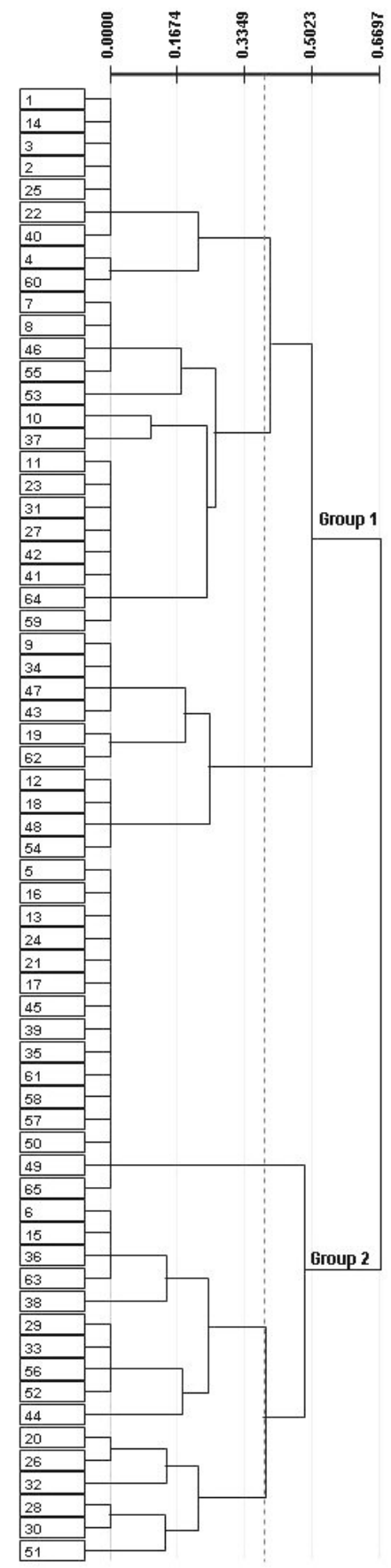


each group. Table 3 summarizes the characteristics of the two groups, highlighting the main differences in coded responses and how responses were articulated (based on coding system outlined in Table 1) and organizational membership and individual characteristics, such as length and nature of work experience.

The two groups differ in their organizational and stakeholder composition. Group 1 includes predominately country nationals working for government and local NGOs. Those who work for international NGOs and donor agencies (at the program or site level) dominate Group 2. Members of Group 2 generally responded in terms of what a successful or failed CCA is (the picture of success) whereas respondents in Group 1 more often considered what was needed for a successful CCA, or what contributed to a failed one (ingredients for success). Given the characteristics and composition of each group, from here on Group 1 is referred to as the "Locally focused group" and Group 2 as the "Big picture group." The following section will examine the composition and characteristics of these two groups of respondents.

\section{Locally Focused Group}

The Locally focused group was largely concerned with the intricacies of CCAs and how to reach a successful outcome. Respondents, with one exception, did not mention sustainability. It would be presumptuous to conclude that respondents in this group do not view the sustainability of Pacific CCAs as important or essential, but they did not frame their response around it.

The Locally focused group concentrated on the ways, means, and requirements for success. Rarely was success itself defined or explained. Respondents in this group often provided a list of ingredients for success such as:

- no land disputes

- community is literate

- community volunteer their time

- effective work structure

- $\quad$ skilled manager working with the conservation area for community's long-term benefit
- enough agricultural land for community

- $\quad$ marketing and training of income generating activities.

"Appropriate management style" and "operations and structure" were emphasized by this group. Few discussed local capacity for management; instead the focus was on a locally appropriate, bottom-up, participatory approach to management. Respondents stressed that when planning and managing a CCA, consideration should be given to the local communities' "social and cultural variables, needs and interpretations of conservation." "Local benefits" through empowerment and involvement were emphasized.

The "nature of external involvement" was considered by most in this group, and included outsider awareness and sensitivity to local cultures, structures, and protocols in their intervention. This also encompassed outsiders respecting local needs and timeframes, and ensuring open and honest communication with the community. Failure would be when:

... the conservation area is not communitybased at all - where a top-down approach by outsiders is imposed... and there is little interest or support among the community for the conservation area initiative.

The local style of Pacific CCAs was central to responses. There was an emphasis on the need for realistic expectations from both the community and external stakeholders. Realistic expectations equate to flexibility in time and approach and a focus on local needs. Success would result:

if program implementers concentrated on the community needs rather than the donor expectations or their own institutional needs.

Failure for some members of this group included a focus on global conservation agendas rather than local needs and desires, as this leads to "unreasonable donor expectations."

The self-sufficiency and complete independence of CCAs was generally not considered a realistic option by this group. Some thought the idea of shortterm, high-impact interventions leading to sustainable community conservation management 
Table 3. Characteristics of the two groups of respondents identified through cluster analysis based on coded responses to the survey questions. Group characteristics are detailed in relation to responses at the subcategory level, how responses were articulated, the organizational composition of each group, the individual respondent's experience and time working with Pacific CCAs.

\begin{tabular}{|c|c|c|c|}
\hline \multicolumn{2}{|c|}{ Characteristics-Points of Difference } & \multirow{2}{*}{$\begin{array}{l}\text { Group } 1 \\
\text { Not a focus: } 3 \%(n=1) \text { noted } \\
\text { sustainability in their success } \\
\text { response }\end{array}$} & \multirow{2}{*}{$\begin{array}{l}\text { Group } 2 \\
\text { Major focus: } 100 \%(n=31) \text { noted } \\
\text { sustainability in their success } \\
\text { response }\end{array}$} \\
\hline Broad category level & Sustainability & & \\
\hline Sub-category level & $\begin{array}{l}\text { Adequate capacity to } \\
\text { manage }\end{array}$ & $\begin{array}{l}\text { Not a focus: Noted by } 27 \% \text { of } \\
\text { this group }\end{array}$ & $\begin{array}{l}\text { Major focus: Noted by } 77 \% \text { of } \\
\text { this group }\end{array}$ \\
\hline Sub-category level & Type of support & $\begin{array}{l}\text { Not a focus: Noted by } 35 \% \text { of } \\
\text { this group }\end{array}$ & $\begin{array}{l}\text { Major focus: Noted by } 74 \% \text { of } \\
\text { this group }\end{array}$ \\
\hline $\begin{array}{l}\text { How responses were } \\
\text { articulated }\end{array}$ & Ingredient or Picture & $\begin{array}{l}\text { Majority }(60 \%) \text { noted the } \\
\text { ingredients of success }\end{array}$ & $\begin{array}{l}\text { Majority }(59 \%) \text { considered the } \\
\text { picture of success }\end{array}$ \\
\hline Group composition & Organization composition & $\begin{array}{l}\text { Dominated by representatives } \\
\text { from in-country governments and } \\
\text { local NGOs }\end{array}$ & $\begin{array}{l}\text { Dominated by representatives } \\
\text { from funder agencies (donors) and } \\
\text { International NGOs }\end{array}$ \\
\hline Respondent experience & $\begin{array}{l}\text { a. Program (regional) } \\
\text { b. Program (country) } \\
\text { c. Project (system/site) }\end{array}$ & $\begin{array}{l}\text { a. } 26 \% \\
\text { b. } 30 \% \\
\text { c. } 44 \%\end{array}$ & $\begin{array}{l}\text { a. } 61 \% \\
\text { b. } 23 \% \\
\text { c. } 16 \%\end{array}$ \\
\hline Time & $\begin{array}{l}<5 \text { years } \\
>5 \text { years }\end{array}$ & $\begin{array}{l}38 \%<5 \text { years } \\
62 \%>5 \text { years }\end{array}$ & $\begin{array}{l}50 \%<5 \text { years } \\
50 \%>5 \text { years }\end{array}$ \\
\hline
\end{tabular}

was unrealistic. It was commonly argued that support (advisory, technical, financial) from external parties should be ongoing.

Most respondents from both groups noted resourcerelated issues. Members of the Locally focused group more frequently noted "locally defined resource" elements. These included consideration of local sociocultural aspects and local resource use in the design of the CCA.

To summarize, the emphasis of the Locally focused group was on the practical workings and needs of successful CCAs in the Pacific region. Many in this group were based with Pacific island governments, NGOs, or CCAs, and operate on more of a local level than the Big picture group. It can be assumed they are not necessarily exposed to regional or global discourse at the same level as international actors. Responses generally reflected their experience and were often specific to a particular CCA or CCA system.

\section{Big Picture Group}

Respondents in the Big picture group generally regarded CCA sustainability as the ultimate measure of success. For a CCA to be "truly successful ... it would be self-sustaining in the longer-term." The other success elements mentioned by respondents in this group were those influencing site sustainability, including external support, adequate community capacity, ecological viability, and structures to "allow sustainability to occur.'

Full community independence in management was considered to be fundamental for success. The general assumption of this group was that CCAs would be externally initiated and funded for a short period until the local community had adequate capacity to manage without external assistance. Failure was commonly considered to be if momentum was lost, "shortly after funding ends." 
Most respondents in the Big picture group discussed the "type of external involvement" in a successful CCA. In doing so, they established the boundaries of how outsiders should and should not be involved in CCAs. "Type of external involvement" for this group encompassed issues such as money, time, and general support; for example, "short-term financial intervention and advice" and "short-term financial/ technical support." Collaboration between external parties and the community may occur but anything more than this may result in "donor dependency," a state that members of this group commonly mentioned in their failure response.

Many in the Big picture group identified the need for community structures and authority to be respected and supported by external bodies. Ongoing technical and legislative support from government (but not from the funder) was seen by some in this group to be important. Without this support, the potential difficulties faced by the community could render the area unsustainable as a management entity. The "type of external support" also included the influence of the external party. Minimal external influence, relates to sustainability because it was argued it would encourage the CCA to be "community driven" and decrease the likelihood of momentum ending when external support ends.

"Adequate local capacity" to manage the CCA after the external party pulls out was noted by most of the group. This included managerial, technical, financial, and scientific capacity. The development of community capacity was considered by some to be the role of outside organizations who should:

build capacity for conservation and be prepared to empower communities...[to enable them to] manage the conservation area after the outside organizations pull out.

In summary, the Big picture group was focused on the broader issues surrounding successful implementation of Pacific island CCAs. Their focus was on sustainability of local CCA management and conservation, how external parties should be involved (time, money, impact), and the local community's capacity to fulfil the ideal of independent sustained and effective management of the CCA. Outsiders from funder agencies and international NGOs dominated this group. Many came from outside the region and operated on a broad program level. Their collective vision of success may, therefore, be related to the regional and global lessons learned and contemporary protected area discourse that they would be exposed to through their organization, as well as their organization's vision and approach.

\section{DISCUSSION: INTERPRETING INSIDER PERCEPTIONS OF SUCCESS}

The primary objective of this investigation was to explore the way success in Pacific island CCAs is perceived by outsiders. The exploratory nature of the survey provided insight into the different ways in which outsiders conceive and articulate success and failure in Pacific island CCAs, and their varied expectations for these areas. Although all participants identified and discussed the common elements of successful CCAs, the relative importance of the elements cannot be determined. The categories and sub-categories of the classification system do not occur in any order and are not commensurable. The strength of this survey and its value to discourse are in revealing diversity. Where the exploratory nature of the survey has prevented firm conclusions but suggested likely explanations, we have raised these points under the heading of "speculation." Further research is required to examine these issues and their relative importance in more detail.

The results demonstrate that:

- perceptions of success are diverse and reflect, to some extent, an individual's experience and history;

- two broad perspectives exist-one focused on the bigger regional and global picture and the other focused on the local situation;

- ecological factors are not always the primary focus of success or failure;

- the community is central to success definitions; and

- expectations for CCAs are high.

Within the international conservation community there is an emphasis on measuring success in protected areas by strictly biological and ecological indicators (Murray 2005). Garnett et al. (2007), in their examination of the effectiveness of Integrated 
Conservation and Development Projects (ICDPs), highlight that failure is generally related to biodiversity loss. We found that perceptions of success in the Pacific islands are diverse; ecological or biological success represents only one dimension and was among the least dominant in perceptions of success. Bruner et al. (2001) argue that the end product is conservation success and social factors are the means. Social factors are, therefore, important to monitor in order to mitigate threats that might compromise future conservation success. Respondents in this study, however, identified social factors as both means (ingredient) and ends (picture) of success.

The results demonstrate that outsiders working with CCAs in the Pacific islands have a strong appreciation of the complexities and issues of the region. However, Pacific CCA evaluations do not necessarily reflect this understanding. Evaluations continue to focus on objectives set by outsiders and conservation success. Although there have been significant changes in the ways protected areas and people are represented over the past 30-40 years, the objectives and how we define and measure success have not necessarily changed.

\section{Defining Success and Failure}

Difficulties in answering questions about success and failure were noted by respondents. Many acknowledged that the subjective nature of success means it can be interpreted on a number of levels. Contemporary evaluation discourse stresses that success is a measure of progress in achieving goals and objectives (Margoluis 1998, Salafsky et al. 2002, Robinson and Redford 2004, Stem et al. 2005). Few respondents noted goals and objectives in their responses. More commonly, the virtues, characteristics, and requirements of a successful CCA were discussed. Some acknowledged that these will not necessarily guarantee success. Findings from community-conserved projects around the world have argued similar positions (Hulme and Murphree 1999, Rhoads et al. 1999). It is argued that if all factors of success are not addressed, success may still occur and alternatively, if all factors are pursued, success still cannot be guaranteed (Salafsky et al. 1999, Pomeroy et al. 2001). Success is not only subjective but also highly context specific.
The focus on the importance of getting it right is topical in contemporary discourse, in which success is often considered in terms of what makes or leads to success (e.g., Pollnac and Crawford 2000, Halpern 2003, Christie et al. 2005). It also reflects the lessons emerging from conservation and development projects, which stress that blueprint plans are inappropriate because each area will vary greatly at the micro and meso level, and their interaction with the macro level; context and process are critical in each initiative (Salafsky et al. 1999, Wells and McShane 2004). This was reflected in most survey responses, which emphasized contextual and process aspects and stressed the importance of understanding the sociocultural context of CCAs.

Speculation: The subjective and context-specific nature of success may be why respondents often focused on the elements of success rather than defining success. This may be related to the relative infancy of contemporary CCAs, the need for flexibility and experimentation and, therefore, evolving goals and objectives, or an assumed ideal of success (i.e., conservation success). Regardless, it highlights the issues and problems of defining success itself and the inherent difficulties this will pose when reporting to funders in these terms.

\section{Experience, Values, and Perceptions of Success}

Experience and history, among other things, will influence interpretations of success and failure. Although shared perceptions of success did not fall entirely within stakeholder groupings, analysis demonstrated a relationship between responses and organizational alignment. The Big picture group was composed predominately of funders and international NGOs, whereas in-country government and local NGO affiliates dominated the Locally focused group. This supports the argument that conceptions of success will be influenced by an individual's social and cultural setting (Fan and Karnilowicz 1997, Werbner 1999). Information, experience, and knowledge will generally be disseminated within an organization, regardless of the level of the individual. The organization's vision, values, and goals will be known and shared, to various degrees, among members (Mascia 2004). Therefore, although there is diversity in expectations and perceptions, some consistency and patterns are evident. 
Speculation: The potential for individuals from the Big picture group to be involved in international discourse, and be aware of and have access to the plethora of information and current thinking, is potentially much higher than those from local government agencies and local NGOs. This is probably why they were thorough in their responses, covering all broad categories and, therefore, the major aspects of contemporary CCA thought.

\section{Realistic Expectations or Utopian Ideals?}

After describing success, some respondents commented on current and future prospects for success in the region. Several respondents referred to some successes, but only two respondents (both field based) indicated that they knew of successful CCAs. Many, especially from the Big picture group, stressed the lack of successful CCAs in the region. These summations are based on the individuals' expectations of Pacific island CCAs. Expectations will influence whether an individual or group perceives an initiative to be a success or failure.

Respondents' expectations of success rest largely, but not solely, with the local community as the "locus of control." Survey results indicate that the values, beliefs, virtues, and characteristics that the local community should have are extensive. These requirements and characteristics, when considered with the current lack of perceived successful CCAs, highlight the issue of outsiders' expectations. Some respondents, after defining success or the necessary requirements for success, commented that this was not actually possible or realistic.

Speculation: There was an underlying assumption made by many respondents that a Pacific CCA will begin as short-term (3 to 5 years), externally initiated and supported project. Projects are, by their very nature, short-term interventions, often aimed at catalyzing long-term change (Sayer and Wells 2004). The emphasis on "sustainability" for the Big picture group may be related to a history of projects in which activities have ceased once the project ends. Success is, therefore, a measure of sustained management, free of externally derived financial and technical dependencies. It has been asserted that it is not realistic to expect short-term guidance and financial support to result in successful communitybased conservation initiatives (Aswani and Hamilton 2004). It could be argued that these CCAs are bound to fail because the model proposed is resource intensive, and local communities do not have available resources to maintain the initiative without external support.

Anticipations of perfection, which the idea of success can conjure, are bound to disappoint. Is the reason for failure, therefore, related to the inability of sites to achieve success, or to ambitious expectations of the process and the community themselves? It is argued that ICDPs were based on naïve assumptions and were overly ambitious (Brown 2003, Wells et al. 2004). CCAs may be falling victim to similar optimism and assumptions on what they can deliver and they may well fall short of such unrealistic expectations.

\section{Diversity of Goals, Expectations, and Perceptions}

Effective evaluation of CCAs will require understanding of the diverse values, interests, expectations, and perceptions of success that apply to these areas. For any given intervention, there will be many parties and actors with their own goals and perceptions of the initiative, its purpose, and success (Conley and Moote 2003). Perceptions and values will differ between outsiders and local communities (Axford 2007). In some cases, their goals and objectives may be consistent, but more likely these will differ greatly (Berkes 2004). Few respondents commented that CCA success should be considered from the perspective of the community, at the center of the initiative. There is a need to challenge conventional thinking and preconceptions of success, by whom and how it is defined.

\section{CONCLUSION}

The question of success is not an issue confined to CCAs; it is a fundamental issue in conservation theory and practice (Murray 2005). The success debate is pertinent because it influences and reflects how CCAs are designed, implemented, managed, and assessed. Perceptions of success will continue to define conservation initiatives and influence support from all actors. If the discussion of success is not embraced and attitudes toward success in CCAs revealed, there is a risk of the management approach becoming stagnant and past mistakes being repeated. 
Responses to this article can be read online at:

http://www.ecologyandsociety.org/voll3/iss2/art45/responses/

\section{Acknowledgments:}

We thank the many experts throughout the Pacific and around the world who participated in this research and shared their invaluable experience, knowledge, and perspectives. Thanks to Malcolm Kennedy for providing assistance with statistical analysis. Malcolm Kennedy and Dona Whiley provided helpful comments on the draft manuscript.

\section{LITERATURE CITED}

Alder, J. 1996. Have tropical marine protected areas worked? An initial analysis of their success. Coastal Management 24(2):97-114.

Aldridge, A., and K. Levine. 2001. Surveying the social world: principles and practice in survey research. Buckingham, Open University Press.

Agardy, T., P. Bridgewater, M. P. Crosby, J. Day, P. K. Dayton, R. Kenchington, D. Laffoley, P. McConney, P. A. Murray, J. E. Parks, and L. Peau. 2003. Dangerous targets? Unresolved issues and ideological clashes around marine protected areas. Aquatic Conservation: Marine and Freshwater Ecosystems 13(4):353-367.

Aswani, S. 2005. Customary sea tenure in Oceania as a case of rights-based fishery management: does it work? Reviews in Fish Biology and Fisheries 15 (3):285-307.

Aswani, S., and R. Hamilton. 2004. The value of many small vs. few large marine protected areas in the Western Solomon Islands. SPC Traditional Marine Resource Management and Knowledge 16:3-14.

Axford, J. 2007. What constitutes success in Pacific island community conserved areas? Unpublished thesis. University of Queensland, St. Lucia Campus, Brisbane, Australia.

Babbie, E. 2005. The basics of social research. Thomson/Wadsworth, Belmont, California, USA.
Baines, G., P. Hunnam, M.-J. Rivers, and B. Watson. 2002. South Pacific Biodiversity Conservation Programme terminal evaluation mission: final report. United Nations Development Programme, New York, New York, USA.

Belbin, L. 1995. PATN: users guide. CSIRO, Canberra, Australia.

Berkes, F. 2004. Rethinking community-based conservation. Conservation Biology 18(3):621630 .

Berkes, F. 2007. Community-based conservation in a globalized world. Proceedings of the National Academy of Sciences of the United States of America 104(39):15188-15193.

Borrini-Feyerabend, G., A. Kothari, and G. Oviedo. 2004. Indigenous and local communities and protected areas - towards equity and enhanced conservation: guidance on policy and practice for co-managed protected areas and community conserved areas. World Commission on Protected Areas (WCPA), IUCN, Gland, Switzerland and Cambridge, UK.

Bray, J. R., and J. T. Curtis. 1957. An ordination of upland forest communities of southern Wisconsin. Ecological Monographs 27:325-349.

Brechin, S. R., P. R. Wilshusen, C. Fortwangler, and P. West. 2002. Beyond the square wheel: toward a more comprehensive understanding of biodiversity conservation as social and political process. Society and Natural Resources 15(1):4164.

Brown, K. 2003. Integrating conservation and development: a case of institutional misfit. Frontiers in Ecology and the Environment 1(9):479-487.

Bruner, A. G., R. E. Gullison, R. E. Rice, and G. A. B. da Fonseca. 2001. Letters: parks and factors in their success-response. Science 293(5532):10451047.

Bryman, A. 2001. Social research methods. Oxford University Press, New York, New York, USA.

Christie, P. 2004. Marine protected areas as biological successes and social failures in Southeast Asia. American Fisheries Society Symposium 2004:1-10. 
Christie, P., K. Lowry, A. T. White, E. G. Oracion, L. Sievanen, R. S. Pomeroy, R. B. Pollnac, J. M. Patlis, and R.-L. V. Eisma. 2005. Key findings on the sustainability of integrated coastal management processes. MPA News 7(2):4-5.

Cinner, J. 2005. Socioeconomic factors influencing customary marine tenure in the Indo-Pacific. Ecology and Society 10(1): 36. [online] URL: http: //www.ecologyandsociety.org/vol10/iss1/art36/.

Cinner, J., and T. McClanahan 2006. Socioeconomic factors that lead to overfishing in small-scale coral reef fisheries of Papua New Guinea. Environmental Conservation 33(1): 73-80.

Conley, A., and M. A. Moote. 2003. Evaluating collaborative natural resource management. Society and Natural Resources 16(5):371-386.

Crawford, B. R., M. Kasmidi, F. Korompis, and R. B. Pollnac. 2006. Factors influencing progress in establishing community-based marine protected areas in Indonesia. Coastal Management 34:39-64.

Fan, C., and W. Karnilowicz. 1997. Measurement of definitions of success among Chinese and Australian girls. Journal of Cross-Cultural Psychology 28(5):589-600.

Garnett, S. T., J. Sayer, and J. du Toit. 2007. Improving the effectiveness of interventions to balance conservation and development: a conceptual framework. Ecology and Society 12(1): 2. [online] URL: http://www.ecologyandsociety.org/ vol12/iss 1/art2/.

Gerber, L. R., D. P. DeMaster, and S. P. Roberts. 2000. Measuring success in conservation. American Scientist 88(4):316.

Halpern, B.S. 2003. The impact of marine reserves: do reserves work and does reserve size matter? Ecological Applications 13(1):S117-S137.

Horwich, R., and J. Lyon. 2007. Community conservation: practitioners' answer to critics. Oryx 41(3):376-385.

Hulme, D., and M. Murphree. 1999. Communities, wildlife and the 'new conservation' in Africa. Journal of International Development 11:277-285.
Kates, R. W., T. M. Parris, and A. A. Leiserowitz. 2005. What is sustainable development? Goals, indicators, values, and practice. Environment 47 (3):8-21.

Lepp, A., and Holland, S. 2006. A comparison of attitudes toward state-led conservation and community-based conservation in the village of Bigodi, Uganda. Society and Natural Resources 19 (7): 609-623.

Mangione, T. W. 1995. Mail surveys: improving the quality. Sage Publications, Thousand Oaks, California, USA.

Margoluis, C. 1998. Measure of success: designing, managing and monitoring conservation and development projects. Island Press, Washington, D.C., USA.

Mascia, M. B. 2004. Social dimensions of marine reserves. Pages 164-186 in J. A. Sobel and C. P. Dalgren, editors. Marine reserves: a guide to science, design, and use. Island Press, Washington, D.C., USA.

McCallum, R., and Sekhran. 1997. Race for the rainforest: evaluating lessons from an integrated conservation and development 'experiment' in New Ireland, PNG. Papua New Guinea Biodiversity Conservation and Resource Management Programme, Waigani, Papua New Guinea.

Murray, G. 2005. Multifaceted measures of success in two Mexican marine protected areas. Society and Natural Resources 18(10):889-905.

Parrish, J. D., D. P. Braun, and R. S. Unnasch. 2003. Are we conserving what we say we are? Measuring ecological integrity within protected areas. Bioscience 53(9):851-860.

Patton, M. Q. 2002. Qualitative research and evaluation methods. Sage Publications, Thousand Oaks, California, USA.

Phillips, A. 2003. Turning on their head: the new paradigm for protected areas. Pages 1-28 in $\mathrm{H}$. Jaireth and D. Smyth, editors. Innovative governance: indigenouspeoples, local communities and protected areas. Ane Books, New Delhi, Chenai, and Kolkata, India.

Pollnac, R. B., and B. R. Crawford. 2000. 
Discovering factors that influence the success of community-based marine protected areas in the Visayas, Philippines. Coastal Resources Center, University of Rhode Island, Kingston, Rhode Island, USA and Philippine Council for Aquatic and Marine Research and Development, Manila, Philippines.

Pollnac, R. B., B. R. Crawford, and M. L. G. Gorospe. 2001. Discovering factors that influence the success of community-based marine protected areas in the Visayas, Philippines. Ocean and Coastal Management 44:683-710.

Pomeroy, R. S., B. M. Katon, and I. Harkes. 2001. Conditions affecting the success of fisheries comanagement: lessons from Asia. Marine Policy 25 (3):197-208.

Pomeroy, R. S., R. B. Pollnac, B. M. Katon, and C. D. Predo. 1997. Evaluating factors contributing to the success of community-based coastal resource management: the Central Visayas Regional Project-1, Philippines. Ocean and Coastal Management 36:97-120.

Rhoads, B. L., D. Wilson, M. Urban, and E. E. Herricks. 1999. Interaction between scientists and nonscientists in community-based watershed management: emergence of the concept of stream naturalization. Environmental Management 24 (3):297-308.

Robinson, J. G., and K. H. Redford. 2004. Jack of all trades, master of none: inherent contradictions among ICD approaches. Pages 10-34 in T. O. McShane and M. Wells, editors. Getting biodiversity projects to work: towards more effective conservation and development. Columbia University Press, New York, USA.

Roe, D., J. Mayers, M. Grieg-Gran, A. Kothari, C. Fabricius, and R. Hughes. 2000. Evaluating Eden: exploring the myths and realities of community-based wildlife management. Series Overview Evaluating Eden 8. International Institute for Environment and Development, London, UK.

Salafsky, N., H. Cauley, G. Balachander, B. Cordes, J. Parks, C. Margoluis, S. Bhatt, C. Encarnacion, D. Russell, and R. Margoluis. 2001. A systematic test of an enterprise strategy for community-based biodiversity conservation. Conservation Biology 15(6):1585-1595.
Salafsky, N., B. Cordes, J. Parks, and C. Hochman. 1999. Evaluating linkages between business, the environment, and local communities: final analytical results from the biodiversity conservation network. Biodiversity Support Program, Washington, D.C., USA.

Salafsky, N., R. Margoluis, K. H. Redford, and J. G. Robinson. 2002. Improving the practice of conservation: a conceptual framework and research agenda for conservation science. Conservation Biology 16(6): 1469-1479.

Sayer, J., and M. P. Wells. 2004. The pathology of projects. Pages 35-48 in T. O. McShane and M. P. Wells, editors. Getting biodiversity projects to work: towards more effective conservation and development. Columbia University Press, New York, New York, USA.

Sekhran, N. 1996. Pursuing the "D" in integrated conservation and development projects (ICADPs): issues and challenges for Papua New Guinea. Rural Development Forestry Network, London, UK.

Smith-Korfmacher, K. 1998. Invisible successes, visible failures: paradoxes of ecosystem management in the Albemarle-Pamlico estuarine study. Coastal Management 26(3):191-211.

Stem, C., R. Margoluis, N. Salafsky, and M. Brown. 2005. Monitoring and evaluation in conservation: a review of trends and approaches. Conservation Biology 19(2):295-309.

van Helden, F. 1998. Between cash and conviction: the social context of the Bismarck-Ramu integrated conservation and development project. National Research Institute Monograph 33. The National Research Institute, Papua New Guinea.

Webb, E. L., R. J. Maliao, and S. V. Siar. 2004. Using local user perceptions to evaluate outcomes of protected area management in the Sagay Marine Reserve, Philippines. Environmental Conservation 31(4):138-148.

Wells, M. P., and T. O. McShane. 2004. Integrating protected area management with local needs and aspirations. Ambio 33(8):513-519.

Wells, M. P., T. O. McShane, H. T. Dublin, S. O'Connor, and K. Redford. 2004. The future of 
integrated conservation and development projects: building on what works. Pages 397-422 in T. O. McShane and M. P. Wells, editors. Getting biodiversity protects to work: towards more effective conservation and development. Columbia University Press, New York, New York, USA.

Werbner, P. 1999. What colour 'success'? Distorting value in studies of ethnic entrepreneurship. The Sociological Review 47:548-579. 